Article

\title{
Modification to L-H Kinetics Model and Its Application in the Investigation on Photodegradation of Gaseous Benzene by Nitrogen-Doped $\mathrm{TiO}_{2}$
}

\author{
Peng Sun ${ }^{\circledR}$, Jun Zhang, Wenxiu Liu, Qi Wang and Wenbin Cao * \\ School of Materials Science and Engineering, University of Science and Technology Beijing, Beijing 100083, \\ China; ustbsunpeng@163.com (P.S.); zhangjunustb@foxmail.com (J.Z.); liuwenxiu@outlook.com (W.L.); \\ wangqi15@ustb.edu.cn (Q.W.) \\ * Correspondence: wbcao@ustb.edu.cn; Tel.: +86-010-6233-2457
}

Received: 11 July 2018; Accepted: 6 August 2018; Published: 9 August 2018

\begin{abstract}
In this paper, the Langmuir-Hinshelwood (L-H) model has been used to investigate the kinetics of photodegradation of gaseous benzene by nitrogen-doped $\mathrm{TiO}_{2}\left(\mathrm{~N}-\mathrm{TiO}_{2}\right)$ at $25{ }^{\circ} \mathrm{C}$ under visible light irradiation. Experimental results show that the photoreaction coefficient $k_{p m}$ increased from $3.992 \times 10^{-6} \mathrm{~mol} \cdot \mathrm{kg}^{-1} \cdot \mathrm{s}^{-1}$ to $11.55 \times 10^{-6} \mathrm{~mol} \cdot \mathrm{kg}^{-1} \cdot \mathrm{s}^{-1}$ along with increasing illumination intensity. However, the adsorption equilibrium constant $K_{L}$ decreased from 1139 to $597 \mathrm{~m}^{3} \cdot \mathrm{mol}^{-1}$ when the illumination intensity increased from $36.7 \times 10^{4} \mathrm{~lx}$ to $75.1 \times 10^{4} \mathrm{~lx}$, whereas it was $2761 \mathrm{~m}^{3} \cdot \mathrm{mol}^{-1}$ in the absence of light. This is contrary to the fact that $K_{L}$ should be a constant if the temperature was fixed. This phenomenon can be attributed to the breaking of the adsorption-desorption equilibrium by photocatalytically decomposition. To compensate for the disequilibrium of the adsorption-desorption process, photoreaction coefficient $k_{p m}$ was introduced to the expression of $K_{L}$ and the compensation form was denoted as $K_{m} . K_{L}$ is an indicator of the adsorption capacity of $\mathrm{TiO}_{2}$ while $K_{m}$ is only an indicator of the coverage ratio of $\mathrm{TiO}_{2}$ surface. The modified L-H model has been experimentally verified so it is expected to be used to predict the kinetics of the photocatalytic degradation of gaseous benzene.
\end{abstract}

Keywords: modified L-H model; $\mathrm{N}-\mathrm{TiO}_{2} ;$ photocatalytic degradation; benzene

\section{Introduction}

Gaseous benzene released from paints, artificial panel or furniture is threatening to human health, particularly for children. However, the gaseous benzene in indoor air is difficult remedy with traditional methods due to its low concentration (ppm or ppb level) [1-3]. However, $\mathrm{TiO}_{2}$ can decompose gaseous benzene under ultraviolet light irradiation, thus it has attracted growing attention [4-8]. In fact, the photodegradation of gaseous benzene by $\mathrm{TiO}_{2}$ photocatalyst is a heterogeneous reaction occurring at a gas-solid interface, and the reaction rate is strongly affected by the environmental factors, particularly illumination intensity [9-11]. So the kinetic study of photocatalytic reaction is important for revealing the effect of these factors on the photocatalytic reaction rate.

The heterogeneous reaction includes two consecutive steps. Firstly, the reactants are adsorbed on the surface of the photocatalysts and secondly, the photocatalytic reaction commences. Generally, the adsorption rate is slower than the photocatalytic reaction rate. So the overall photocatalytic reaction rate is mainly dominated by the adsorption rate. Furthermore, the adsorption rate can be equivalently expressed using the coverage ratio of the adsorbed reactants on the surface of the photocatalysts [12-15]. So the photocatalytic reaction rate $r$ can be expressed as Equation (1) [16-18], which is widely known as the original L-H model.

$$
r=-\frac{d c}{d t}=k_{p} \theta
$$


where $c$ is the concentration of the reactant, $t$ is the photocatalytic reaction time, $\theta$ is the coverage ratio of pollutants on the $\mathrm{TiO}_{2}$ surface, $k_{p}$ is photoreaction coefficient.

According to Langmuir adsorption theory, the coverage ratio is related to adsorption capacity and the concentration of the reactant. $K_{L}$ was defined as adsorption equilibrium constant to measure the adsorption capacity of $\mathrm{TiO}_{2}$ and coverage ratio $\theta$ can be expressed as Equation (2) according to adsorption theory [19].

$$
\theta=\frac{K_{L} c}{1+K_{L} c}
$$

Input $\theta$ from Equation (2) to Equation (1), the photoreaction coefficient $r$ can be expressed as Equation (3) [20-22],

$$
r=k_{p} \frac{K_{L} c}{1+K_{L} c}
$$

Equation (3) is the much known expression of L-H model and has been widely used in investigating the kinetics of photocatalytic reactions. Lin et al. [23] studied the photocatalytic degradation pathway of dimethyl sulfide. They used original and derivative L-H models to study the kinetics under different temperatures and found that temperature can enhance photocatalytic activity. Dhada et al. [24] investigated the photocatalytic degradation of benzene by $\mathrm{TiO}_{2}$ under sunshine and UV light. They found that UV light can promote photocatalytic reaction than visible light due to its higher energy of the photons. Cheng et al. [25] studied the photocatalytic degradation of benzene. They found that higher temperature, illumination intensity and humidity can promote the reaction rate greatly.

The works mentioned above are focused in revealing the effect of environmental factors such as illumination intensity, the amount of the photocatalyst and some processing parameters on the photodegradation ratio. However, the effect of illumination intensity on adsorption equilibrium coefficient of gaseous pollutant was neglected in most articles. In liquid phase photocatalysis, some authors have reported their research on the effect of the illumination intensity on both the photoreaction coefficient and the adsorption coefficient [26-29]. Du [30] found that the value of the adsorption coefficient calculated from the L-H model was illumination intensity-dependent in photodegradation of liquid dimethyl phthalate (DMP).

Coincidentally, it has also been found that the adsorption coefficient has been affected by light intensity in the gaseous photocatalytic reactions [31,32]. Brosillon [31] studied the kinetic model of photocatalytic degradation of butyric acid, and they found that the adsorption coefficient $K_{R}$ can be expressed as Equation (4)

$$
K_{R}=\frac{\left(k_{r L H} C_{R a d s 0}+k_{d 1}+k_{d 2}^{\prime} I\right) K}{k_{d 1}+k_{d 2}^{\prime} I}
$$

where $k_{r L H}$ is the reaction rate of the reaction between $\cdot \mathrm{OH}$ and reactants, $k_{d 1}, k_{d 2}^{\prime}$ is the decomposition rate of $\cdot \mathrm{OH}$ in the routes of $\cdot \mathrm{OH} \rightarrow \mathrm{OH}^{-}+\mathrm{h}^{+}$and $\cdot \mathrm{OH}+\mathrm{e}^{-} \rightarrow \mathrm{OH}^{-}, I$ is the light intensity, $K$ is the adsorption constant without light irradiation. Their results indicate that the adsorption coefficient in gas photocatalytic reaction is a function of light intensity, which is not reasonable as the adsorption coefficient should be a constant under a fixed temperature. And, the parameter $k r_{L H}, k_{d 1}, k_{d 2}^{\prime}$ are difficult to calculate as the concentration of $\cdot \mathrm{OH}$ is difficult to accurately measure [33] during the process of photocatalytic degradation of benzene and its concentration changes during the progression of the photocatalytic reaction. So this model is not applicable to predict the concentration of the reactant at different reaction times under different illumination intensities. He [32] investigated the degradation of benzene by mesoporous $\mathrm{TiO}_{2}$ and also found that the adsorption coefficient could be affected by light intensity. They attributed it to the decrease of available active sites as the increased photo-induced radicals will occupy more of the active sites under higher illumination intensity. However, the effect of photocatalytic decomposition of the adsorbed benzene by the increased radicals on the adsorption coefficient was not considered. So, it's necessary to accurately describe the relationship between the adsorption coefficient and the illumination intensity in gaseous photocatalytic reactions. 
In the present work, the effect of illumination intensity on photoreaction coefficient $k_{p m}$ and adsorption equilibrium coefficient has been studied under a constant $25^{\circ} \mathrm{C}$. Photoreaction coefficient was introduced as the modification to $K_{L}$ and the compensation $K_{m}$ was used to replace $K_{L}$ in the original L-H model. The modified L-H model can reveal the interaction between the adsorption, desorption and photo-oxidation process. The results showed that the $K_{m}$ and $k_{p m}$ can be obtained under different illumination intensity at $25^{\circ} \mathrm{C}$, thus the concentration at different reaction times can be predicted.

\section{Results and Discussion}

\subsection{Characterization of the $\mathrm{N}-\mathrm{TiO}_{2}$ Photocatalysts}

The $\mathrm{N}-\mathrm{TiO}_{2}$ catalysts were characterized by X-ray diffraction (XRD), Transmission electron microscopy (TEM), UV-Vis spectra (UV-Vis) and X-ray photoelectron spectroscopy (XPS) and the results were illustrated in Figure 1. Figure 1a shows the XRD patterns of $\mathrm{N}-\mathrm{TiO}_{2}$. It is clear that all the diffraction peaks were indexed to that of anatase $\mathrm{TiO}_{2}$ (JCPDS no. 21-1272). The crystal size calculated by Scherrer's Equation was also around $10.2 \mathrm{~nm}$. Figure $1 \mathrm{~b}$ shows the morphology of the $\mathrm{N}-\mathrm{TiO}_{2}$ powders. It can be found that the prepared sample was composed of spherical $\mathrm{TiO}_{2}$ and the size was ranged from 9 to $12 \mathrm{~nm}$, which is in consistent with the calculated result. The light absorption spectrum was measured by UV-Vis spectrum and was shown in Figure 1c. It is well known that the bandgap of pristine anatase is $3.2 \mathrm{eV}$, while the light absorption has been extended into the ranged of 400 to $600 \mathrm{~nm}$ of as-prepared $\mathrm{N}-\mathrm{TiO}_{2}$. And its bandgap energy was $2.9 \mathrm{eV}$ shown in the inset of Figure 1c calculated by using the method in other works [34,35]. The chemical state of N1s was also investigated by XPS and the result was shown in Figure 1d. Only one peak located at $399.9 \mathrm{eV}$ can be found, which can be attributed to the interstitial doping of nitrogen into $\mathrm{TiO}_{2}$ lattice with $\mathrm{Ti}-\mathrm{O}-\mathrm{N}$ bond [36].



(a)



(b)

Figure 1. Cont. 


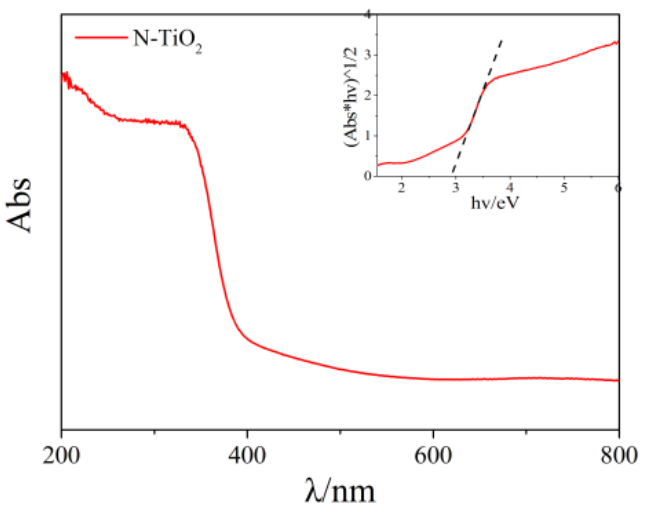

(c)

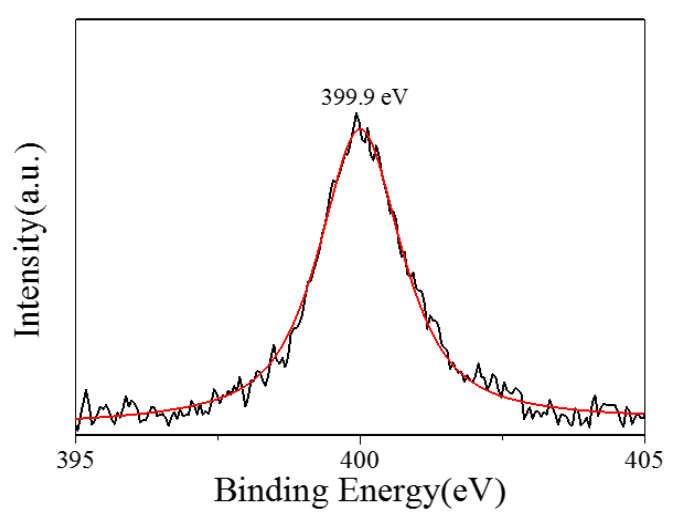

(d)

Figure 1. Characterization of $\mathrm{N}-\mathrm{TiO}_{2}$ catalysts (a) XRD patterns, (b) TEM image, (c) UV-Vis spectrum, (d) N1s binding energy peak.

\subsection{Kinetic Study of Photocatalytic Degradation of Benzene under Different Illumination Intensity}

Figure 2 shows the variation of benzene concentration with photocatalytic degradation time under different illumination intensities. It shows that the concentration of benzene remained almost unchanged during the first hour without light irradiation, indicating that adsorption and desorption processes of benzene on $\mathrm{TiO}_{2}$ surface have reached equilibrium, thus the decrease of benzene after illumination can be ascribed to the photocatalytic degradation process. When it was illuminated for $4 \mathrm{~h}$ under different illumination intensity of $36.7 \times 10^{4}, 46.9 \times 10^{4}, 61.7 \times 10^{4}$ and $75.1 \times 10^{4} \mathrm{~lx}$, the removal ratio of benzene was $72.1 \%, 84 \%, 90 \%$ and $92.4 \%$, respectively. The removal ratio increased dramatically under higher illumination intensity, indicating that illumination intensity can promote the photocatalytic degradation performance.

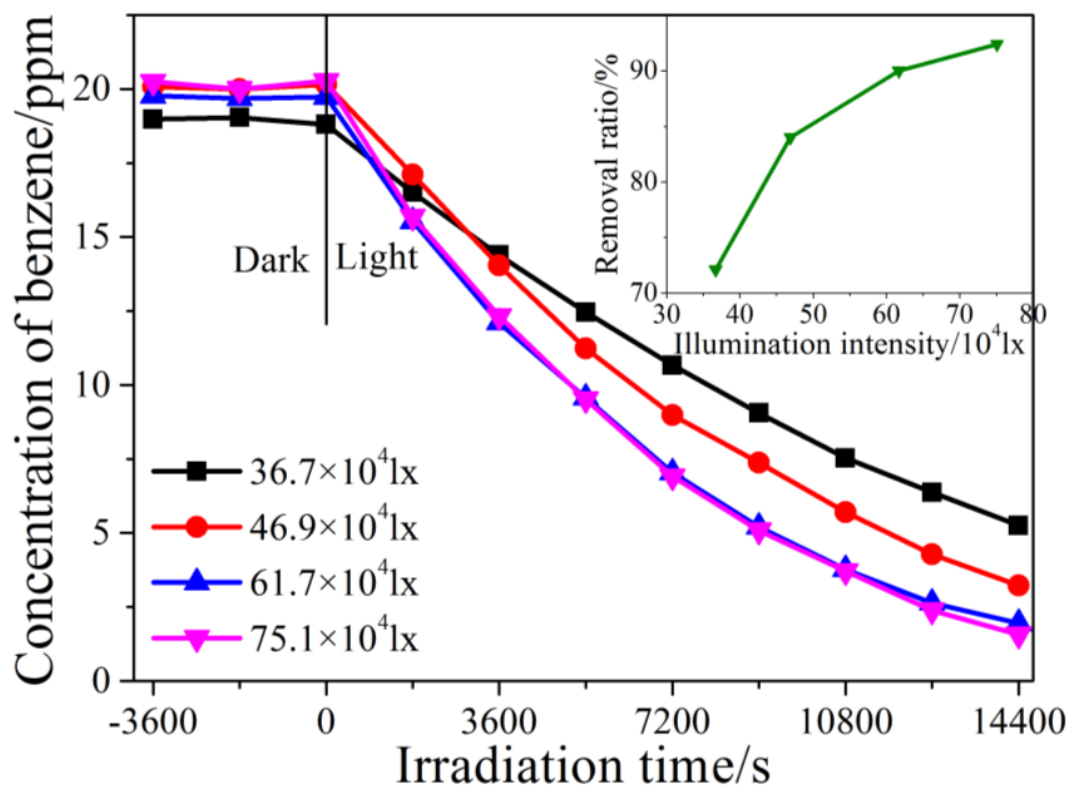

Figure 2. Variation of benzene concentration vs. photocatalytic degradation time under different illumination intensity. 
During the photocatalytic degradation process, the amount of degraded benzene per unit time can be calculated by Equation (5).

$$
\Delta n=r V=-\frac{d c}{d t} V
$$

where $\Delta n$ is the amount of degraded benzene per unit time, $r$ is the photocatalytic degradation rate, $V$ is the volume of the reactor, $c$ is concentration of benzene and $t$ is photocatalytic degradation time. The detailed form of $r$ is shown by original L-H model in Equation (3) [32,37], so after inputting $r$ from Equation (3) to Equation (5), we can get

$$
\Delta n=-\frac{d c}{d t} V=k_{p} \frac{K_{L} c}{1+K_{L} c}
$$

In Equation (6), $k_{p}$ is the photoreaction coefficient of the whole reaction system and is related to the mass of the catalysts. So the photocatalytic degradation rate coefficient per unit mass $k_{p m}$ can be expressed in Equation (7)

$$
k_{p m}=\frac{k_{p}}{m}
$$

Input $k_{p m}$ from Equation (7) into Equation (6), then we can get

$$
-\frac{d c}{d t} V=m k_{p m} \frac{K_{L} c}{1+K_{L} c}
$$

So the relationship between $d c$ and $d t$ can be expressed in Equation (9)

$$
-\frac{V}{m k_{p m}} \frac{1+K_{L} c}{K_{L} c} d c=d t
$$

The relationship between $c$ and $t$ can be obtained after making integration to Equation (9), that is

$$
-\frac{V}{k_{p m} m} \int_{c_{0}}^{c} \frac{1+K_{L} c}{K_{L} c} d c=\int_{0}^{t} d t
$$

The result of Equation is

$$
t=\frac{V}{m k_{p m}}\left[\left(c_{0}-c\right)+\frac{1}{K_{L}}\left(\ln c_{0}-\ln c\right)\right]
$$

After rearranging in terms of $1 /\left(c_{0}-c\right)$, the linear form of Equation (11) is obtained.

$$
\frac{\ln \left(c_{0} / c\right)}{c_{0}-c}=\frac{m}{V} k_{p m} K_{L} \frac{t}{c_{0}-c}-K_{L}
$$

In Equation (12), it can be found that $\ln \left(c_{0} / c\right) /\left(c_{0}-c\right)$ and $t /\left(c_{0}-c\right)$ is a linear relationship, and the slope and intercept of the line is $m k_{p m} K_{L} / V$ and $K_{L}$ respectively.

Figure 3 shows the plots of $\ln \left(c_{0} / c\right) /\left(c_{0}-c\right)$ vs. $t /\left(c_{0}-c\right)$ under different illumination intensity. According to the obtained slopes and intercepts, the values of $k_{p m}$ and $K_{L}$ were calculated and summarized in Table 1 . And the standard deviation $R^{2}$ for each case were also listed in Table 1. 


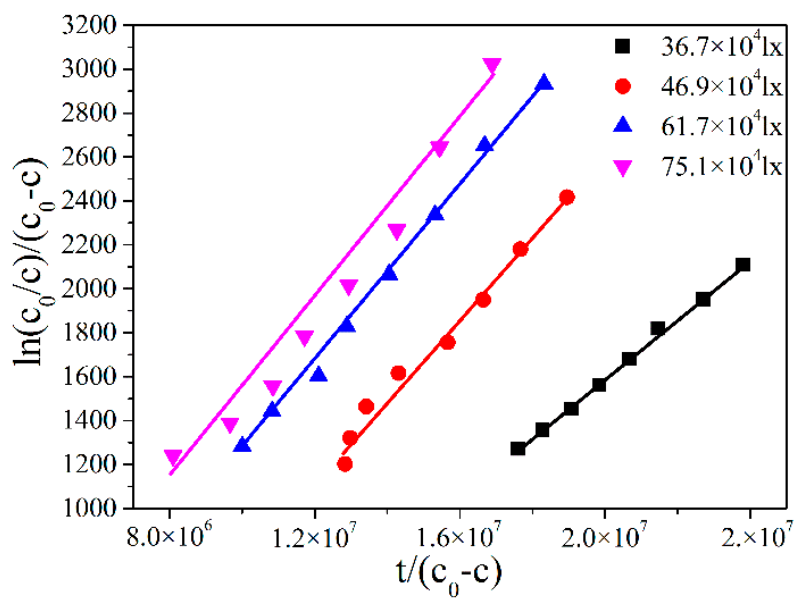

Figure 3. Plots of $\ln \left(c_{0} / c\right) /\left(c_{0}-c\right)$ vs. $t /\left(c_{0}-c\right)$ under different illumination intensity. (solid points: experimental results; solid line(curve): fitted results).

Table 1. Calculated $K_{p m}$ and $K_{L}$ under different illumination intensity using the original L-H model.

\begin{tabular}{|c|c|c|c|}
\hline Illumination Intensity/10 $1 x$ & $\begin{array}{c}k_{p m} / \\
10^{-6} \mathrm{~mol} \cdot \mathrm{kg}^{-1} \cdot \mathrm{s}^{-1}\end{array}$ & $\begin{array}{c}K_{L} / \\
\mathrm{m}^{3} \cdot \mathrm{mol}^{-1}\end{array}$ & $\mathbf{R}^{2}$ \\
\hline 36.7 & 3.992 & 1139 & 0.9981 \\
\hline 46.9 & 5.731 & 1064 & 0.9847 \\
\hline 61.7 & 8.589 & 791 & 0.9961 \\
\hline 75.1 & 11.55 & 597 & 0.9674 \\
\hline
\end{tabular}

It can be seen from Table 1 that $k_{p m}$ was calculated as $3.992 \times 10^{-6}, 5.371 \times 10^{-6}, 8.589 \times 10^{-6}$, $11.55 \times 10^{-6} \mathrm{~mol} \cdot \mathrm{kg}^{-1} \cdot \mathrm{s}^{-1}$ corresponding to the illumination intensity of $36.7 \times 10^{4}, 46.9 \times 10^{4}$, $61.7 \times 10^{4}$, and $75.1 \times 10^{4} \mathrm{~lx}$, respectively. And $k_{p m}$ increased greatly with increases in illumination intensity, which means that the photodegradation rate of benzene can be significantly promoted by increasing the illumination intensity in our experiment conditions. It's reasonable that the increased illumination intensity means more photon irradiated on $\mathrm{TiO}_{2}$ surface, that can produce more $\cdot \mathrm{OH}$, which is the main radical in photocatalytic reaction. According to other works [32], photoreaction rate coefficient $k_{p m}$ depends on illumination intensity in a power law

$$
k_{p m}=\alpha I^{n}
$$

The value of intensity coefficient $\alpha$ and exponent $\mathrm{n}$ was $2.24 \times 10^{-14}$ and 1.482 obtained by using the results in Table 1.

And the value of adsorption constant $K_{L}$ was decreased from $1139 \mathrm{~m}^{3} \cdot \mathrm{mol}^{-1}$ to $597 \mathrm{~m}^{3} \cdot \mathrm{mol}^{-1}$ when the illumination intensity was increased from $36.7 \times 10^{4} \mathrm{~lx}$ to $75.1 \times 10^{4} \mathrm{~lx}$. That is, $K_{L}$ varied with the variation of the illumination intensity. However, the adsorption constant $K_{L}$ is related to the temperature and should be a constant as the temperature of the reactor was carefully maintained at $25{ }^{\circ} \mathrm{C}$ according to Langmuir adsorption theory. So the obtained results are inconsistent with the basic fact that the $K_{L}$ should be kept unchanged if the temperature was fixed for a certain adsorption-desorption balance, which shows that original L-H model cannot be used to describe the photocatalysis processes accurately.

Generally, it is widely recognized that the photocatalytic degradation of gaseous chemicals mainly includes two steps, gas adsorption on the surface of the photocatalyst and photodegradation. After the gas chemicals were adsorbed on the surface of the photocatalyst, certain amount of the adsorbed molecules were decomposed by photocatalytic degradation. 
However, the original L-H model only considers the adsorption and desorption equilibrium of the gas molecules on the surface of the photocatalyst. So the amount of the adsorbed benzene molecules $\Delta n_{a}$ and lost desorbed benzene molecules $\Delta n_{d}$ of $\mathrm{N}-\mathrm{TiO}_{2}$ surface per unit time can be defined as Equation (14) and Equation (15) respectively [38].

$$
\begin{gathered}
\Delta n_{a}=k_{a} c(1-\theta) S \\
\Delta n_{d}=k_{d} \theta S
\end{gathered}
$$

where $k_{a}$ and $k_{d}$ is adsorption and desorption constant of benzene and is all thermodynamic constant.

When adsorption and desorption process reach equilibrium, there is $\Delta n_{a}=\Delta n_{d}$, and the detailed form is shown in Equation (16).

$$
k_{a} c(1-\theta) S=k_{d} \theta S
$$

So coverage ratio $\theta$ and adsorption equilibrium constant $K_{L}$ can be obtained [19]

$$
\begin{gathered}
\theta=\frac{k_{a} c}{k_{d}+k_{a} c}=\frac{\frac{k_{a}}{k_{d}} c}{1+\frac{k_{a} c}{k_{d}} c} \\
K_{L}=\frac{k_{a}}{k_{d}}
\end{gathered}
$$

$K_{L}$ is thermodynamically constant due to $k_{a}$ and $k_{d}$ being thermodynamic constants, and is an indication of adsorption ability of the catalysts. While in photocatalytic reaction, the degradation process would cause the decrease of benzene on $\mathrm{TiO}_{2}$ surface, which is equivalent to the increase in the desorption rate of benzene molecules. So the equilibrium between adsorption and desorption process would be broken. However, adsorption equilibrium constant $K_{L}$ is only related to $k_{a}$ and $k_{d}$ in Equation (18), which make it impossible to reveal the effect of degradation process on the equilibrium. Therefore, original L-H model based on Langmuir adsorption theory is not entirely suitable for the photocatalytic degradation of benzene and necessary modification should be applied to original L-H model for better understanding kinetics of the photocatalysis process.

\subsection{Modication to the L-H Model and Kinetic Results under Different Illumination Intensity}

In the photocatalytic reaction, there are three processes: Adsorption, desorption and the photocatalytic degradation process. The photocatalytic degradation process will cause decrease of benzene molecules on interface, so the amount of lost benzene molecules $\Delta n_{b}$ is the sum of desorbed and photocatalytic degraded benzene molecules per unit time.

$$
\Delta n_{b}=k_{d} \theta S+k_{p m} \theta S
$$

Combing Equation (13) and (18), the coverage ratio $\theta$ becomes

$$
\begin{aligned}
& \theta=\frac{k_{a} c}{k_{d}+k_{p m}+k_{a} c}=\frac{\frac{k_{a}}{k_{d}+k_{p m}} c}{1+\frac{k_{a}}{k_{d}+k_{p m}} c}=\frac{K_{m} c}{1+K_{m} c} \\
& K_{m}=\frac{k_{a}}{k_{d}+k_{p m}}=\frac{k_{d}}{k_{d}+k_{p m}} \frac{k_{a}}{k_{d}}=\frac{k_{d}}{k_{d}+k_{p m}} K_{L}
\end{aligned}
$$

$k_{a} /\left(k_{d}+k_{p m}\right)$ can be defined as coverage coefficient $K_{m}$ in Equation (21). The coverage coefficient $K_{m}$ is a function of $k_{a}, k_{d}$ and $k_{p m}$, so $K_{m}$ is not thermodynamic constant due to $k_{p m}$ is photodynamic. The value of $K_{m}$ is equal to that of $K_{L}$ while there is no light due to $k_{p m}$ is zero without irradiation. And the value of $k_{p m}$ will increase greatly under high illumination intensity, thus will result in a decrease of $K_{m}$, which is in accordance with the experimental results in Table 1. 
The original L-H model can be modified by using $K_{m}$ to replace $K_{L}$ in Equation (13) and (14) there is

$$
\begin{gathered}
t=\frac{V}{m k_{p m}}\left[\left(c_{0}-c\right)+\frac{1}{K_{m}}\left(\ln c_{0}-\ln c\right)\right] \\
\frac{\ln \left(c_{0} / c\right)}{c_{0}-c}=\frac{m}{V} k_{p m} K_{m} t \frac{1}{c_{0}-c}-K_{m}
\end{gathered}
$$

The expression form of Equation (23) is similar to that of original L-H model except coverage coefficient $K_{m}$ and equilibrium coefficient $K_{L} . K_{L}$ in original L-H model is an indicator of adsorption capacity of $\mathrm{TiO}_{2}$, while $K_{m}$ is the indicator of the amount of benzene on $\mathrm{TiO}_{2}$ surface. The parameters $k_{p m}$ and $K_{m}$ can be obtained through the plots of $\ln \left(c_{0} / c\right) /\left(c_{0}-c\right)$ vs. $t /\left(c_{0}-c\right)$ which were shown in Figure $4 \mathrm{a}$ and the results were listed in Table 2. And after taking reciprocal on both sides of Equation (21), the linear relationship exists between $1 / K_{m}$ and $k_{p m}$ can be found in Equation (24) and was shown in Figure $4 \mathrm{~b}$. Then the values of $k_{a}, k_{d}$ and $K_{L}$ can also be obtained and summarized in Table 2. The value of $K_{L}$ in modified L-H model is $2629 \mathrm{~m}^{3} \cdot \mathrm{mol}^{-1}$ under different illumination intensity at $25^{\circ} \mathrm{C}$, which is consistent with Langmuir adsorption theory. The value of $k_{a}$ and $k_{d}$ is constant in a given temperature at $25^{\circ} \mathrm{C}$ and the relationship of $k_{p m}$ and $I$ is revealed in Equation (14), thus $K_{m}$ under different illumination intensity can be obtained by Equation (21). Therefore, the concentration $c$ at different photocatalytic reaction time $t$ under different illumination intensity $I$ can be predicted from Equation (22)

$$
\frac{1}{K_{m}}=\frac{k_{p m}}{k_{a}}+\frac{k_{d}}{k_{a}}
$$

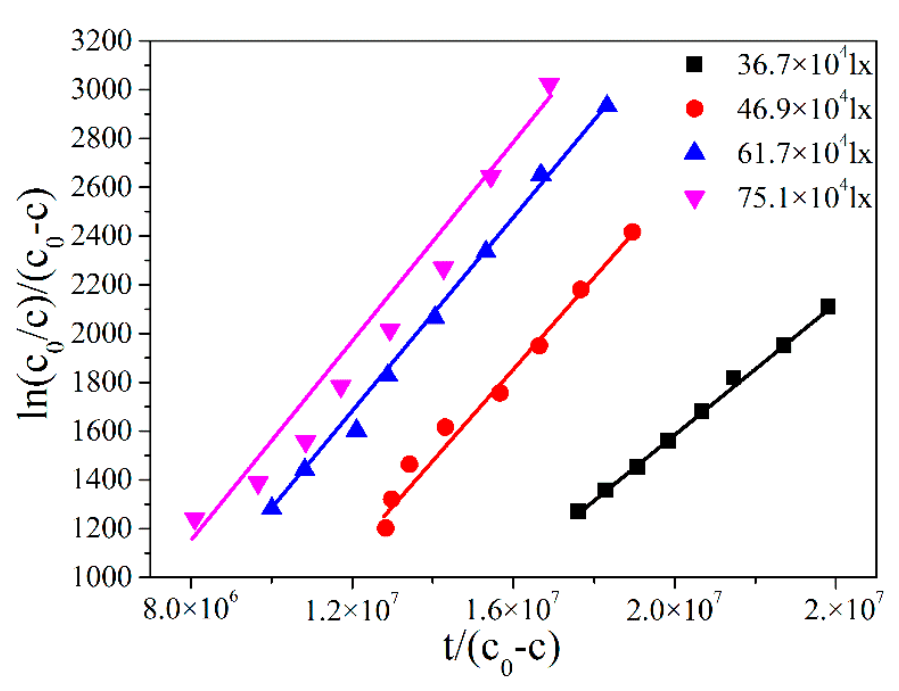

(a)

Figure 4. Cont. 


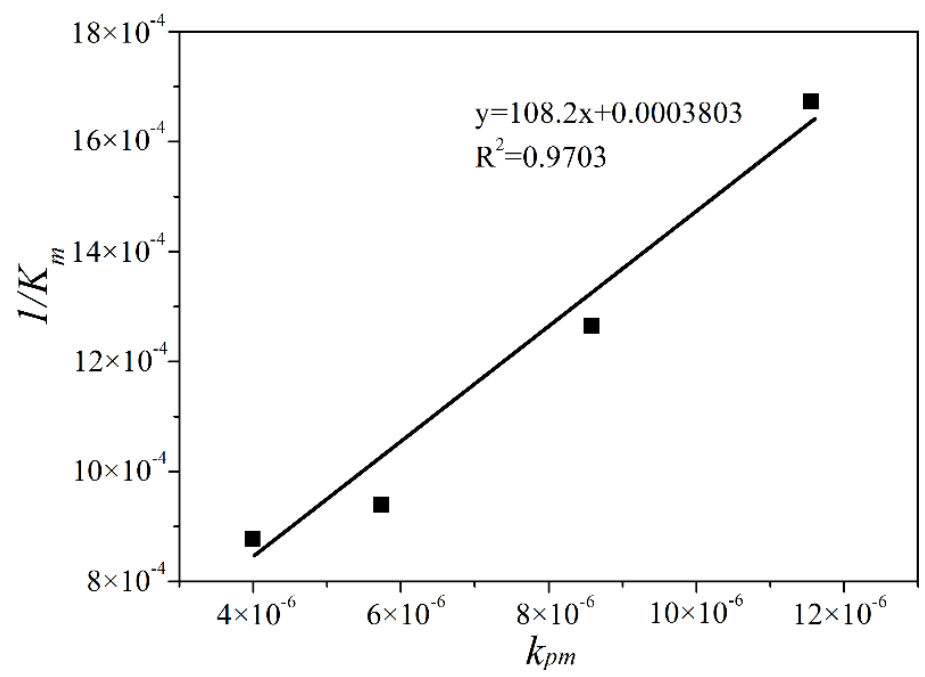

(b)

Figure 4. The relationship of the kinetic parameters in modified L-H model (a) The linear of $\ln \left(c_{0} / c\right) /$ $\left(c_{0}-c\right)$ vs. $t /\left(c_{0}-c\right),(\mathbf{b})$ The linear of $1 / K_{m}$ vs. $k_{p m}$ (solid points: experimental results; solid line(curve): Fitted results).

Table 2. Results of modified L-H model under different illumination intensity.

\begin{tabular}{|c|c|c|c|c|c|}
\hline $\begin{array}{l}\text { Illumination } \\
\text { Intensity } / 10^{4} 1 x\end{array}$ & $\begin{array}{c}\text { Photoreaction } \\
\text { Coefficient } \\
k_{p m} / 10^{-6} \mathrm{~mol} \cdot \mathrm{kg}^{-1} \cdot \mathrm{s}^{-1}\end{array}$ & $\begin{array}{c}\text { Coverage } \\
\text { Coefficient } \\
K_{m} / \mathrm{m}^{3} \cdot \mathrm{mol}^{-1}\end{array}$ & $\begin{array}{c}\text { Adsorption } \\
\text { Constant } \\
k_{a} / \mathrm{m}^{3} \cdot \mathrm{kg}^{-1 .-1}\end{array}$ & $\begin{array}{c}\text { Desorption } \\
\text { Constant } \\
k_{d} / \mathrm{mol}^{\prime} \mathrm{kg}^{-1} \cdot \mathrm{s}^{-1}\end{array}$ & $\begin{array}{c}\text { Adsorption } \\
\text { Equilibrium Constant } \\
K_{L} / \mathrm{m}^{3} \cdot \mathrm{mol}^{-1}\end{array}$ \\
\hline 36.7 & 3.992 & 1139 & \multirow{4}{*}{$9.242 \times 10^{-3}$} & \multirow{4}{*}{$3.514 \times 10^{-6}$} & \multirow{4}{*}{2629} \\
\hline 46.9 & 5.731 & 1064 & & & \\
\hline 61.7 & 8.589 & 791 & & & \\
\hline 75.1 & 11.55 & 597 & & & \\
\hline
\end{tabular}

\subsection{The Adsorption Equilibrium Constant $K_{L}$ Obtained by Using Adsorption Theory}

In fact, the adsorption equilibrium constant $K_{L}$ is thermodynamically constant and can be used to evaluate the adsorption ability. In Langmuir adsorption theory, the adsorption equilibrium constant $K_{L}$ without light irradiation can be obtained as follow [39-41]:

$$
\frac{c_{0}}{\left(c_{T}-c_{0}\right) V}=\frac{c_{0}}{c_{m} V}+\frac{1}{K_{L} c_{m} V}
$$

where $c_{T}$ is total concentration of benzene filled into the reactor, $c_{0}$ is initial concentration of gaseous benzene after adsorption equilibrium, $c_{m}$ is the maximum concentration that can be adsorbed by $\mathrm{N}-\mathrm{TiO}_{2}$. It is obvious that there is a linear relationship between $c_{0} /\left(c_{T}-c_{0}\right) V$ and $c_{0}$ in Equation (25). By filling different volume of benzene into reactor, $c_{T}$ and $c_{0}$ can be measured after adsorption equilibrium and were summarized in Table 3. The plot of $c_{0} /\left(c_{T}-c_{0}\right) \mathrm{V}$ vs. $c_{0} / c_{m} V$ was shown in Figure 5. The slope and intercept of the linear is $1 / c_{m} V$ and $1 / K_{L} c_{m} V$, respectively. The value of $K_{L}$ was $2761 \mathrm{~m}^{3} \cdot \mathrm{mol}^{-1}$, which is an indicator of the adsorption ability of benzene of $\mathrm{N}-\mathrm{TiO}_{2}$ at $25^{\circ} \mathrm{C}$. 


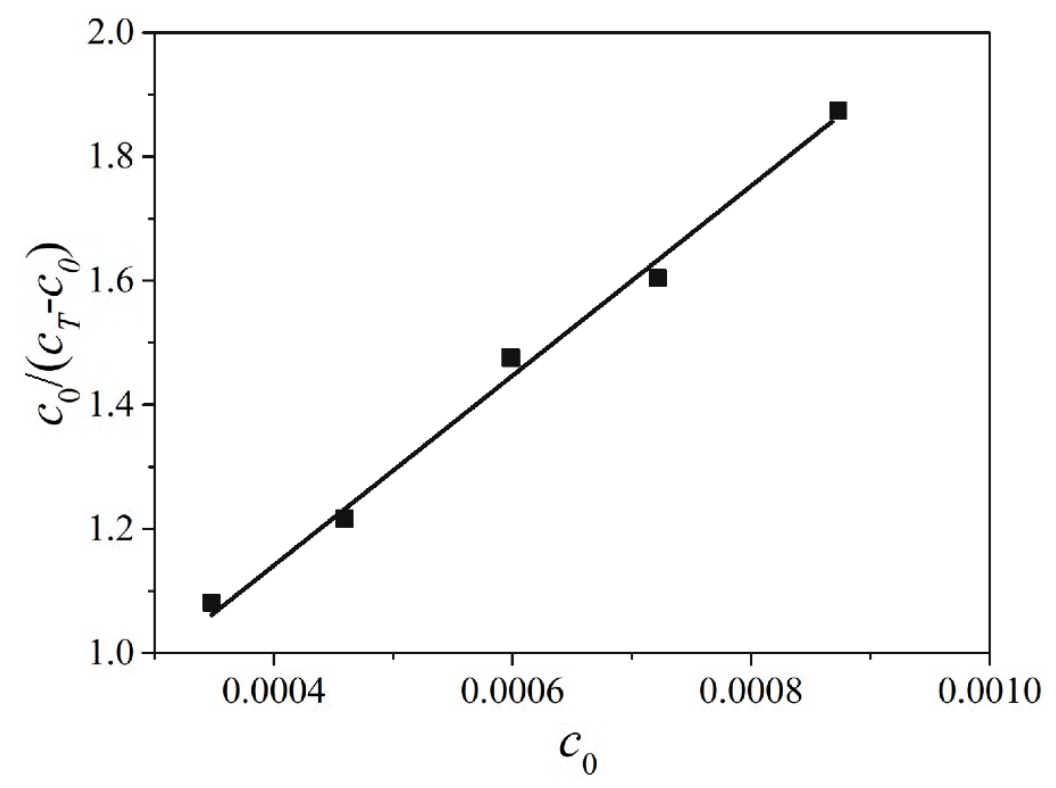

Figure 5. Linear relationship between $c_{0} /\left(c_{T}-c_{0}\right)$ and $c_{0}$ (solid points: experimental results; solid line(curve): fitted results).

Table 3. Concentration of benzene before and after adsorption equilibrium at $25^{\circ} \mathrm{C}$.

\begin{tabular}{cc}
\hline Total Concentration Filled into the Reactor $\boldsymbol{c}_{t} / \mathbf{p p m}$ & Initial Concentration after Adsorption Equilibrium $\boldsymbol{c}_{\mathbf{0}} / \mathbf{p p m}$ \\
\hline 15 & 7.79 \\
18.75 & 10.29 \\
22.5 & 13.41 \\
26.25 & 16.17 \\
30 & 19.56 \\
\hline
\end{tabular}

\subsection{Verification of the Modified L-H Model}

To verify the modified L-H model, the photodegradation of benzene under the illumination intensity of $23.8 \times 10^{4} \mathrm{~lx}$ was carried out by fixing other conditions except the initial concentration of benzene was $14.81 \mathrm{ppm}$. In this case, the calculated $k_{p m}$ and $K_{m}$ is $2.101 \times 10^{-6} \mathrm{~mol} \cdot \mathrm{kg}^{-1} \cdot \mathrm{s}^{-1} \mathrm{~mol}$ and $1645 \mathrm{~m}^{3} \cdot \mathrm{mol}^{-1}$ respectively. By inputting the values of $k_{p m}$ and $K_{m}$ into Equation (22), the predicted concentration variation of benzene vs. irradiation time was obtained, which is shown in Figure 6 (denoted with the black solid line). The experimentally measured concentration of the benzene was denoted with red solid squares in Figure 6. It is clearly seen that the theoretical prediction shows very good agreement with the experimental results. So the modified L-H model can be used to predict benzene concentration under different illumination intensities at a constant temperature. 




Figure 6. The predicted and measured concentration of benzene vs. time.

\section{Materials and Methods}

\subsection{Preparation and Characterization of Samples}

Nanocrystalline $\mathrm{N}-\mathrm{TiO}_{2}$ powders were prepared by hydrothermal method following the route used in our previous work [42]. The phase of the nano powders was determined by X-ray diffraction (XRD) with $\mathrm{Cu} \mathrm{K} \alpha$ source in the $2 \theta$ ranging from 20 to $80^{\circ}$. The morphology of $\mathrm{N}_{-} \mathrm{TiO}_{2}$ was characterized by Transmission electron microscopy (TEM, Hitachi, Jeol 200CX, Tokyo, Japan). UV-Vis spectra of the as-prepared sample was measured by Pgeneral UV-1901 instrument. The valence state of N was characterized by X-ray photoelectron spectroscopy (XPS, Thermo Fisher Scientic, Escalab 250, Waltham, MA, USA). Then the $\mathrm{N}^{-\mathrm{TiO}_{2}}$ catalysts were dispersed into alcohol with ultrasonic wave of $50 \mathrm{kHz}$ by an ultrasonicato (S6103, Aladdin, Shanghai, China) for two hours. After dispersing, the suspension was spray-coated on the surface of $\mathrm{a} \mathrm{SiO}_{2}$ glass substrate $(5 \mathrm{~cm} \times 5 \mathrm{~cm})$ and the amount of coated $\mathrm{N}-\mathrm{TiO}_{2}$ catalysts was $30 \mathrm{mg}$. The $\mathrm{N}-\mathrm{TiO}_{2}$ coated glass was dried in air under $60{ }^{\circ} \mathrm{C}$ for $2 \mathrm{~h}$.

\subsection{Photocatalytic Reaction System}

The schematic setup of the photocatalytic reaction system is illustrated in Figure 7. The cylindrical reactor with $15 \mathrm{~cm}$ in height and $10 \mathrm{~cm}$ in diameter was made of $316 \mathrm{~L}$ stainless steel. The temperature of the reactor were maintained at $25{ }^{\circ} \mathrm{C}$ by a bath circulator. A xenon lamp with a cut-off filter of $420 \mathrm{~nm}$ was used as the visible light illumination source. The illumination intensity could be adjusted at the range of 0 to $80 \times 10^{4} \mathrm{~lx}$. A quartz window was mounted on the reactor for light irradiation. A gas chromatography (GC-2014, Shimadzu, Kyoto, Japan) was connected to the reactor to measure the concentrations of charged benzene in the reactor. The gas chromatography was equipped with Rtx-wax capillary column (Shimadzu) with $60 \mathrm{~m}$ in length, $0.53 \mathrm{~mm}$ in internal diameter and $1.0 \mu \mathrm{m}$ in thickness.

\subsection{Photocatalytic Reaction Procedures}

The $\mathrm{N}-\mathrm{TiO}_{2}$ loaded glass was put into the photocatalytic reaction chamber. After a leakage check, the reactor was pumped to a vacuum of 0.1 atmosphere pressure, then the reactor was irradiated for $24 \mathrm{~h}$ under $254 \mathrm{~nm}$ ultraviolet light to clean the possible pollutants that may be adsorbed on the surface of the photocatalysts and the reactor as well. After a certain volume of benzene was charged/flushed into the reactor, clean air $\left(\mathrm{N}_{2}: \mathrm{O}_{2}=80 \%: 20 \%\right)$ was flushed into the reactor until the inner pressure was balanced with the atmospheric pressure. The concentration of benzene was set at $30 \mathrm{ppm}$ as much as possible. Then the reactor was kept in dark for $60 \mathrm{~min}$ to reach the balance of adsorption-desorption. After that, the xenon lamp was turned on to make the irradiation through the quartz window, while the illumination intensity was adjusted at $36.7 \times 10^{4}, 46.9 \times 10^{4}, 61.7 \times 10^{4}$ and $75.1 \times 10^{4} 1 x$ by 
adjusting the distance between the light source and the sample. The concentration of the benzene in the reactor was measured and recorded every $30 \mathrm{~min}$. The temperature of the reactor was maintained at $25^{\circ} \mathrm{C}$ by a bath circulator.

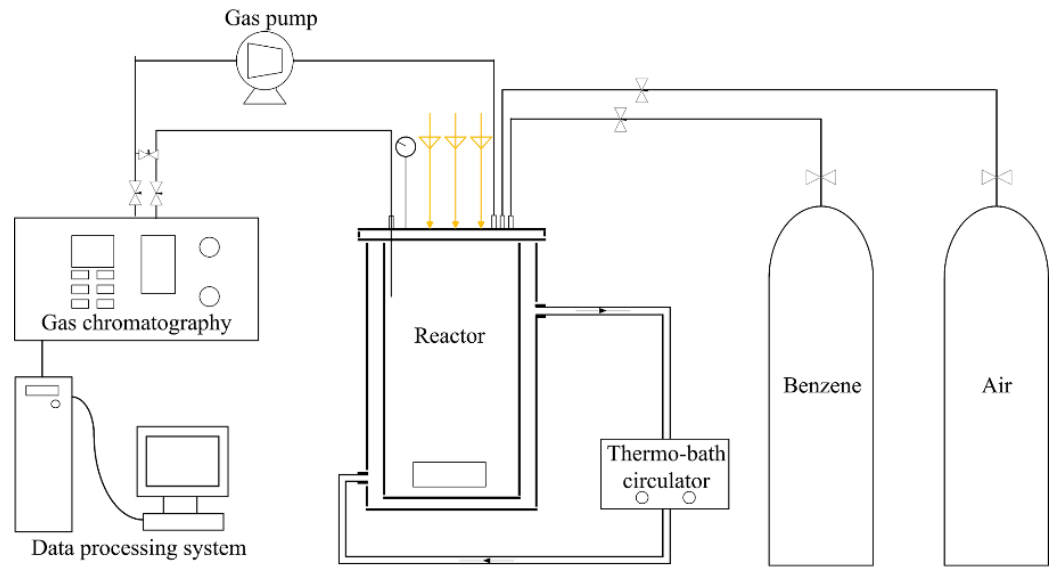

Figure 7. Schematic illustration of the photocatalytic reaction.

\section{Conclusions}

The L-H model has been used to investigate the kinetics of photodegradation of gaseous benzene by $\mathrm{N}-\mathrm{TiO}_{2}$ at $25^{\circ} \mathrm{C}$ under visible light irradiation. Experimental data indicates that the adsorption equilibrium constant $K_{L}$ calculated according to the L-H model decreased from 1139 to $597 \mathrm{~m}^{3} \cdot \mathrm{mol}^{-1}$ when the illumination intensity was increased from $36.7 \times 10^{4} \mathrm{~lx}$ to $75.1 \times 10^{4} \mathrm{~lx}$, whereas it was $2761 \mathrm{~m}^{3} \cdot \mathrm{mol}^{-1}$ when in absence of light. This is contrary to the fact that $K_{L}$ should be a constant if the reaction temperature was fixed. The benzene molecules adsorbed on the surface of the $\mathrm{N}_{-} \mathrm{TiO}_{2}$ were dynamically photodegraded by the photocatalyst and thus the equilibrium of adsorption-desorption was broken would account for that. Photoreaction coefficient $k_{p m}$ was introduced in the L-H model to compensate the disequilibrium of the adsorption-desorption caused by photodecomposition. Experiment result shows that $k_{p m}$ is proportional to the light intensity $I^{1.482}$. As a result, the new parameter $K_{m}\left(k_{a} /\left(k_{d}+k_{p m}\right)\right)$ is closely related to the light intensity. Therefore, the concentration variation of benzene $c$ vs irradiation time $t$ under different light intensity $I$ can be predicted.

Author Contributions: In this paper, P.S., J.Z. and W.L. designed the experiments; P.S., J.Z. and W.L. performed the experiments; P.S., J.Z., W.L. and Q.W. analyzed the data; the manuscript was written by P.S. and edited by W.C.

Funding: This research was funded by the National Key Research and Development Plan of China [Grant Nos. 2016YFC0700901, 2016YFC0700607].

Acknowledgments: This work is financially supported by the National Key Research and Development Plan of China [Grant Nos. 2016YFC0700901, 2016YFC0700607].

Conflicts of Interest: The authors declare no conflict of interest.

\section{References}

1. Sui, H.; Zhang, T.; Cui, J.; Li, X.; Crittenden, J.; Li, X.; He, L. Novel off-gas treatment technology to remove volatile organic compounds with high concentration. Ind. Eng. Chem. Res. 2016, 55, 2594-2603. [CrossRef]

2. Jiang, N.; Hui, C.-X.; Li, J.; Lu, N.; Shang, K.-F.; Wu, Y.; Mizuno, A. Improved performance of parallel surface/packed-bed discharge reactor for indoor VOCs decomposition: Optimization of the reactor structure. J. Phys. D Appl. Phys. 2015, 48, 40. [CrossRef]

3. Ye, C.Z.; Ariya, P.A. Co-adsorption of gaseous benzene, toluene, ethylbenzene, m-xylene (btex) and $\mathrm{SO}_{2}$ on recyclable $\mathrm{Fe}_{3} \mathrm{O}_{4}$ nanoparticles at 0-101\% relative humidities. J. Environ. Sci. 2015, 31, 164-174. [CrossRef] [PubMed] 
4. Zeng, L.; Lu, Z.; Li, M.; Yang, J.; Song, W.; Zeng, D.; Xie, C. A modular calcination method to prepare modified $\mathrm{N}$-doped $\mathrm{TiO}_{2}$ nanoparticle with high photocatalytic activity. Appl. Catal. B Environ. 2016, 183, 308-316. [CrossRef]

5. Ren, L.; Mao, M.; Li, Y.; Lan, L.; Zhang, Z.; Zhao, X. Novel photothermocatalytic synergetic effect leads to high catalytic activity and excellent durability of anatase $\mathrm{TiO}_{2}$ nanosheets with dominant $\{001\}$ facets for benzene abatement. Appl. Catal. B Environ. 2016, 198, 303-310. [CrossRef]

6. Yadav, H.M.; Kim, J.-S. Solvothermal synthesis of anatase $\mathrm{TiO}_{2}$-graphene oxide nanocomposites and their photocatalytic performance. J. Alloys Compd. 2016, 688, 123-129. [CrossRef]

7. Fujimoto, T.M.; Ponczek, M.; Rochetto, U.L.; Landers, R.; Tomaz, E. Photocatalytic oxidation of selected gas-phase VOCs using UV light, $\mathrm{TiO}_{2}$, and $\mathrm{TiO}_{2}$ /Pd. Environ. Sci. Pollut. Res. 2017, 24, 6390-6396. [CrossRef] [PubMed]

8. Wongaree, M.; Chiarakorn, S.; Chuangchote, S.; Sagawa, T. Photocatalytic performance of electrospun $\mathrm{CNT} / \mathrm{TiO}_{2}$ nanofibers in a simulated air purifier under visible light irradiation. Environ. Sci. Pollut. Res. 2016, 23, 21395-21406. [CrossRef] [PubMed]

9. Sabbaghi, S.; Mohammadi, M.; Ebadi, H. Photocatalytic degradation of benzene wastewater using $\mathrm{PANI}^{-\mathrm{TiO}} \mathrm{O}_{2}$ nanocomposite under UV and solar light radiation. J. Environ. Eng. 2016, 142, 05015003. [CrossRef]

10. Fang, J.; Chen, Z.; Zheng, Q.; Li, D. Photocatalytic decomposition of benzene enhanced by the heating effect of light: Improving solar energy utilization with photothermocatalytic synergy. Catal. Sci. Technol. 2017, 7, 3303-3311. [CrossRef]

11. Lan, L.; Li, Y.; Zeng, M.; Mao, M.; Ren, L.; Yang, Y.; Liu, H.; Yun, L.; Zhao, X. Efficient UV-Vis-Infrared light-driven catalytic abatement of benzene on amorphous manganese oxide supported on anatase $\mathrm{TiO}_{2}$ nanosheet with dominant $\{001\}$ facets promoted by a photothermocatalytic synergetic effect. Appl. Catal. B Environ. 2017, 203, 494-504. [CrossRef]

12. Melián, E.P.; Díaz, O.G.; Araña, J.; Rodríguez, J.M.D.; Rendón, E.T.; Melián, J.A.H. Kinetics and adsorption comparative study on the photocatalytic degradation of o-, m- and p-cresol. Catal. Today 2007, 129, $256-262$. [CrossRef]

13. Chen, M.; Bao, C.; Cun, T.; Huang, Q. One-pot synthesis of ZnO/oligoaniline nanocomposites with improved removal of organic dyes in water: Effect of adsorption on photocatalytic degradation. Mater. Res. Bull. 2017, 95, 459-467. [CrossRef]

14. Zhi, Y.; Li, Y.; Zhang, Q.; Wang, H. Zno nanoparticles immobilized on flaky layered double hydroxides as photocatalysts with enhanced adsorptivity for removal of acid red g. Langmuir 2010, 26, 15546-15553. [CrossRef] [PubMed]

15. Dong, W.; Lee, C.W.; Lu, X.; Sun, Y.; Hua, W.; Zhuang, G.; Zhang, S.; Chen, J.; Hou, H.; Zhao, D. Synchronous role of coupled adsorption and photocatalytic oxidation on ordered mesoporous anatase TiO2-SiO2 nanocomposites generating excellent degradation activity of rhb dye. Appl. Catal. B Environ. 2010, 95, 197-207. [CrossRef]

16. Kim, S.B.; Hong, S.C. Kinetic study for photocatalytic degradation of volatile organic compounds in air using thin film $\mathrm{TiO}_{2}$ photocatalyst. Appl. Catal. B Environ. 2002, 35, 305-315. [CrossRef]

17. Golshan, M.; Zare, M.; Goudarzi, G.; Abtahi, M.; Babaei, A.A. $\mathrm{Fe}_{3} \mathrm{O}_{4} @$ hap-enhanced photocatalytic degradation of Acid Red73 in aqueous suspension: Optimization, kinetic, and mechanism studies. Mater. Res. Bull. 2017, 91, 59-67. [CrossRef]

18. Deng, X.-Q.; Liu, J.-L.; Li, X.-S.; Zhu, B.; Zhu, X.; Zhu, A.-M. Kinetic study on visible-light photocatalytic removal of formaldehyde from air over plasmonic $\mathrm{Au} / \mathrm{TiO}_{2}$. Catal. Today 2017, 281, 630-635. [CrossRef]

19. Langmuir, I. The constitution and fundamental properties of solids and liquids. Part I. Solids. J. Am. Chem. Soc. 1916, 38, 2221-2295. [CrossRef]

20. Liu, P.; Yu, X.; Wang, F.; Zhang, W.; Yang, L.; Liu, Y. Degradation of formaldehyde and benzene by $\mathrm{TiO}_{2}$ photocatalytic cement based materials. J. Wuhan Univ. Technol.-Mater. Sci. Ed. 2017, 32, 391-396. [CrossRef]

21. Yuzawa, H.; Aoki, M.; Otake, K.; Hattori, T.; Itoh, H.; Yoshida, H. Reaction mechanism of aromatic ring hydroxylation by water over platinum-loaded titanium oxide photocatalyst. J. Phys. Chem. C 2012, 116, 25376-25387. [CrossRef]

22. Einaga, H.; Mochiduki, K.; Teraoka, Y. Photocatalytic oxidation processes for toluene oxidation over $\mathrm{TiO}_{2}$ catalysts. Catalysts 2013, 3, 219. [CrossRef] 
23. Lin, Y.-H.; Hsueh, H.-T.; Chang, C.-W.; Chu, H. The visible light-driven photodegradation of dimethyl sulfide on S-doped $\mathrm{TiO}_{2}$ : Characterization, kinetics, and reaction pathways. Appl. Catal. B Environ. 2016, 199, 1-10. [CrossRef]

24. Dhada, I.; Nagar, P.K.; Sharma, M. Photo-catalytic oxidation of individual and mixture of benzene, toluene and p-xylene. Int. J. Environ. Sci. Technol. 2016, 13, 39-46. [CrossRef]

25. Cheng, L.; Kang, Y.; Li, G. Effect factors of benzene adsorption and degradation by nano- $\mathrm{TiO}_{2} \mathrm{immobilized}$ on diatomite. J. Nanomaterials 2012, 2012, 6. [CrossRef]

26. Ollis, D.F. Kinetics of liquid phase photocatalyzed reactions: An illuminating approach. J. Phys. Chem. B 2005, 109, 2439-2444. [CrossRef] [PubMed]

27. $\mathrm{Xu}, \mathrm{Y}$.; Langford, C.H. Variation of langmuir adsorption constant determined for $\mathrm{TiO}_{2}$-photocatalyzed degradation of acetophenone under different light intensity. J. Photochem. Photobiol. A Chem. 2000, 133, 67-71. [CrossRef]

28. Giovannetti, R.; Rommozzi, E.; D'Amato, C.; Zannotti, M. Kinetic model for simultaneous adsorption/ photodegradation process of alizarin red $\mathrm{s}$ in water solution by nano- $\mathrm{TiO}_{2}$ under visible light. Catalysts 2016, 6, 84. [CrossRef]

29. Silva, C.G.; Faria, J.L. Effect of key operational parameters on the photocatalytic oxidation of phenol by nanocrystalline sol-gel $\mathrm{TiO}_{2}$ under uv irradiation. J. Mol. Catal. A Chem. 2009, 305, 147-154. [CrossRef]

30. Du, E.; Zhang, Y.X.; Zheng, L. Photocatalytic degradation of dimethyl phthalate in aqueous $\mathrm{TiO}_{2}$ suspension: A modified langmuir-hinshelwood model. React. Kinet. Catal. Lett. 2009, 97, 83-90. [CrossRef]

31. Brosillon, S.; Lhomme, L.; Vallet, C.; Bouzaza, A.; Wolbert, D. Gas phase photocatalysis and liquid phase photocatalysis: Interdependence and influence of substrate concentration and photon flow on degradation reaction kinetics. Appl. Catal. B Environ. 2008, 78, 232-241. [CrossRef]

32. He, F.; Li, J.; Li, T.; Li, G. Solvothermal synthesis of mesoporous $\mathrm{TiO}_{2}$ : The effect of morphology, size and calcination progress on photocatalytic activity in the degradation of gaseous benzene. Chem. Eng. J. 2014, 237, 312-321. [CrossRef]

33. Soltani, T.; Lee, B.-K. Novel and facile synthesis of Ba-doped $\mathrm{BiFeO}_{3}$ nanoparticles and enhancement of their magnetic and photocatalytic activities for complete degradation of benzene in aqueous solution. J. Hazard. Mater. 2016, 316, 122-133. [CrossRef] [PubMed]

34. Chen, S.-H.; Hsiao, Y.-C.; Chiu, Y.-J.; Tseng, Y.-H. A simple route in fabricating carbon-modified titania films with glucose and their visible-light-responsive photocatalytic activity. Catalysts 2018, 8, 178. [CrossRef]

35. Li, C.X.; Jin, H.Z.; Yang, Z.Z.; Yang, X.; Dong, Q.Z.; Li, T.T. Preparation and photocatalytic properties of mesporous $\mathrm{RGO} / \mathrm{TiO}_{2}$ composites. J. Inorg. Mater. 2017, 32, 357-364.

36. Xu, J.; Liu, Q.; Lin, S.; Cao, W. One-step synthesis of nanocrystalline $\mathrm{N}$-doped $\mathrm{TiO}_{2}$ powders and their photocatalytic activity under visible light irradiation. Res. Chem. Intermed. 2013, 39, 1655-1664. [CrossRef]

37. Wang, J.; Ruan, H.; Li, W.; Li, D.; Hu, Y.; Chen, J.; Shao, Y.; Zheng, Y. Highly efficient oxidation of gaseous benzene on novel $\mathrm{Ag}_{3} \mathrm{VO}_{4} / \mathrm{TiO}_{2}$ nanocomposite photocatalysts under visible and simulated solar light irradiation. J. Phys. Chem. C 2012, 116, 13935-13943. [CrossRef]

38. Cong, Y.; Zhang, J.; Chen, F.; Anpo, M.; He, D. Preparation, photocatalytic activity, and mechanism of nano$\mathrm{TiO}_{2}$ co-doped with nitrogen and iron (iii). J. Phys. Chem. C 2007, 111, 10618-10623. [CrossRef]

39. Foo, K.Y.; Hameed, B.H. Insights into the modeling of adsorption isotherm systems. Chem. Eng. J. 2010, 156, 2-10. [CrossRef]

40. Wei, D.; Li, S.; Fang, L.; Zhang, Y. Effect of environmental factors on enhanced adsorption and photocatalytic regeneration of molecular imprinted $\mathrm{TiO}_{2}$ polymers for fluoroquinolones. Environ. Sci. Pollut. Res. 2018, 25, 6729-6738. [CrossRef] [PubMed]

41. Li, Z.; Kim, J.K.; Chaudhari, V.; Mayadevi, S.; Campos, L.C. Degradation of metaldehyde in water by nanoparticle catalysts and powdered activated carbon. Environ. Sci. Pollut. Res. 2017, 24, 17861-17873. [CrossRef] [PubMed]

42. Xu, J.; Sun, P.; Zhang, X.; Jiang, P.; Cao, W.; Chen, P.; Jin, H. Synthesis of N-doped $\mathrm{TiO}_{2}$ with different nitrogen concentrations by mild hydrothermal method. Mater. Manuf. Processes 2014, 29, 1162-1167. [CrossRef]

(C) 2018 by the authors. Licensee MDPI, Basel, Switzerland. This article is an open access article distributed under the terms and conditions of the Creative Commons Attribution (CC BY) license (http://creativecommons.org/licenses/by/4.0/). 